\title{
A Simplified Numerical Simulation Method of Bending Properties for Glass Fiber Cloth Reinforced Denture Base Resin
}

\author{
Yasuhiro TANIMOTO, Tsuyoshi NISHIWAKI ${ }^{1}$, Norihiro NISHIYAMA, \\ Kimiya NEMOTO and Zen-ichiro MAEKAWA ${ }^{2}$ \\ Department of Dental Materials, Research Institute of Oral Science, \\ Nihon University School of Dentistry at Matsudo \\ 2-870-1 Sakaecho Nishi, Matsudo, Chiba 271-8587, Japan \\ ${ }^{1}$ Research and Development Department, ASICS Corporation \\ 6-2-1, Takatsukadai, Nishi-ku, Kobe 651-2271, Japan \\ ${ }^{2}$ Division of Advanced Fibro-Science, Kyoto Institute of Technology \\ Goshokaido-cho, Matsugasaki, Sakyo-ku, Kyoto 606-8585, Japan
}

Received January 11, 2002/Accepted March 26, 2002

The purpose of this study was to propose a new numerical modeling of the glass fiber cloth reinforced denture base resin (GFRP). The proposed model is constructed with an isotropic shell, beam and orthotropic shell elements representing the outmost resin, interlaminar resin and glass fiber cloth, respectively. The proposed model was applied to the failure progress analysis under three-point bending conditions, the validity of the numerical model was checked through comparisons with experimental results. The failure progress behaviors involving the local failures, such as interlaminar delamination and resin failure, could be simulated using the numerical model for analyzing the failure progress of GFRP. It is concluded that the model was effective for the failure progress analysis of GFRP.

Key words: Finite element method, Glass fiber cloth reinforced denture base resin, Failure progress behavior

\section{INTRODUCTION}

Polymethylmethacrylate has been adapted for denture base resin for over fifty years in the dental field, because of its superior handling, good durability, good color tone and excellent mechanical properties. However, various practical problems concerning denture bases that had been damaged for long time have been reported by clinical experiments ${ }^{1)}$. Further, the patient feels discomfort due to the thickness of the denture base when attaching a denture base. Therefore, studies on maintaining the mechanical properties of denture bases but with reduction of denture thickness are required. The reinforcement method of the denture base using glass fiber cloth (GF) is one of the countermeasures answering the request. In general, GF have been extensively used as structural materials in various industrial fields ${ }^{2)}$ such as sport, leisure and spacecraft where the high specific stiffness and strength are required. On the other hand, there are several studies on applications of GF in denture bases ${ }^{3-7)}$. These results suggest that glass fiber cloth reinforced denture base resin (GFRP) has higher mechanical properties than common denture base resins (PM). In general, composite materials such as GFRP are defined as materials fabricated by the combination of 
several kinds of materials. Wide ranges in the mechanical properties of the composite materials may be produced by changing various design parameters, the reinforcement ratio and the insert position of reinforcement. For the effective application of the GFRP to practical dental materials, the most important factor may be the prediction of the mechanical characteristics of the GFRP in advance. However, there have been few studies examining the design of the GFRP ${ }^{8)}$.

The finite element method $\left.{ }^{9,10}\right)(\mathrm{FEM})$ is a powerful tool in the predictions of mechanical properties of the GFRP. For example, the precise prediction of the mechanical properties and failure mechanisms using FEM will be helpful in reducing the number of experiments ${ }^{11,12}$. Moreover, the application of the FEM can produce important information which cannot usually be obtained from experiments ${ }^{13,14)}$. Accordingly, the development of an analytical procedure based on the FEM will become an important guide to GFRP design. The failure progress behavior of GFRP is very complex because of its heterogeneity. In other words, various failures such as interlaminar delamination, transverse cracking and fiber breaking are caused under the strength stress level. To clarify the failure progress of the GFRP, the proposed modeling method must consider the heterogeneity of GFRP. Recently, the progression of tensile damage in unidirectional quasi-isotropic carbon fiber reinforced laminates was successfully simulated using the quasi-three-dimensional model ${ }^{15)}$. This model, constructed with two kinds of elements, can consider the heterogeneity.

In the present study, we applied the quasi-three-dimensional model to the three point bending simulation in order to predict the precise failure progress mechanism of GFRP. After validating its application to the failure progress analysis of GFRP by comparisons with experimental measurements, the failure progress mechanism is discussed.

\section{MATERIALS AND METHODS}

\section{Materials}

The matrix resin for GFRP was a denture base self-curing acrylic resin (PM). A powder-liquid mixed curing method was performed using the ratio, polymethyl methacrylate (Quick resin, Shofu Inc., Kyoto, Japan): methylmetacrylate (Quick resin, Shofu Inc., Kyoto, Japan) of $2: 1$. On the other hand, the reinforcement used was GF (WF 150, Nittobo FRP Laboratory Co., Ltd., Fukushima, Japan) with 0.2 $\mathrm{mm}$ thickness. The coupling agent used was $\gamma$-methacryloxypropyltrimethoxysilane ( $\gamma$-MPTS, Shinetsu Corp., Tokyo, Japan). The GF was treated with $2 \%$ of $\gamma$-MPTS solution, comprised of 70 mass $\%$ ethanol and 30 mass $\%$ water, by utilizing the depping method. The silane-treated GF was then dried at room temperature for 24 hr. The GFRP with three plies of GF in the natural axis of thickness direction, was fabricated. To fabricate the flat plate of the GFRP, matrix resin paste, into which three plies of the GF were inserted, was kept in $16 \mathrm{~cm}^{2}(2 \mathrm{~mm}$ thickness) stainless steel at $3.0 \mathrm{MPa}$ pressure for $1 \mathrm{hr}$ and self-cured. The fabricated GFRP plate was then cut using a diamond wheel and ground using \#800 emery paper to make the 


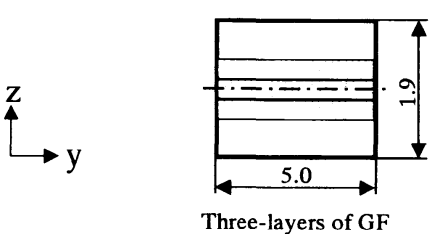

(a) GFRP

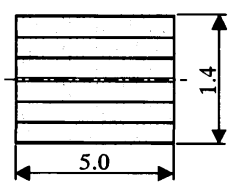

Six-layers of GF

(b) GF

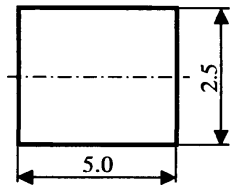

Non - GF

(c) PM

$\square$ Glass fiber cloth (thickness is $0.2 \mathrm{~mm}$ )

Denture base resin

Fig. 1 Schematic diagrams of cross-sectional areas of materials used in this study. Dimensions are $\mathrm{mm}$.

specimen size for the bending test. The specimens for the bending test were rectangular bars of $5 \mathrm{~mm}$ width, $1.9 \mathrm{~mm}$ thickness and $40 \mathrm{~mm}$ length.

In addition, two samples were prepared as controls to obtained material properties to use for FEM calculations. One set of samples is GF material only. This sample was fabricated by laying up to six plies of the GF. To combine a layer with another layer, bisphenol based epoxy resin (Epikote 828, Yuka shell epoxy K. K., Tokyo, Japan) with $11 \mathrm{phr}$ of triethylenetetramine (Wako Pure Chemical Industries Ltd., Osaka, Japan) as a hardening catalyst was used. The GF firmed epoxy resin was heated on $16 \mathrm{~cm}^{2}(2.5 \mathrm{~mm}$ thickness $)$ stainless steel at $100^{\circ} \mathrm{C}$ for $30 \mathrm{~min}, 120^{\circ} \mathrm{C}$ for $1 \mathrm{hr}$ and $130^{\circ} \mathrm{C}$ for $2 \mathrm{hr}$, and then naturally cooled. The geometries of the bending specimens of the GF were rectangular bars of $5 \mathrm{~mm}$ width, $1.4 \mathrm{~mm}$ thickness and 40 $\mathrm{mm}$ length. The other set of samples was PM material only. The procedures for fabrication of the PM are essentially identical with those of the GFRP with the exception not to insert GF in PM. The geometries of the bending specimens of the PM were rectangular bars of $5 \mathrm{~mm}$ width, $2.5 \mathrm{~mm}$ thickness and $40 \mathrm{~mm}$ length.

As mentioned above, the cross-sectional areas of the three samples used in this study were GFRP, GF and PM as shown in Fig. 1.

\section{Three point bending test}

Three point bending tests were performed at a constant loading speed of $2 \mathrm{~mm} / \mathrm{min}$ at a span length of $30 \mathrm{~mm}$ using a computer controlled INSTRON testing machine (TCM500CR, Minebea Co., Ltd., Tokyo, Japan).

\section{Numerical modeling}

The finite element model proposed here is based on the quasi-three-dimensional modeling method ${ }^{15-17)}$. Figure 2 shows the basic concept for the quasi-three-dimensional model. In this modeling, each layer is divided into three layers, a fiber concentrated layer and two remaining resin layers. The laminated composite is assumed to be a laminated structure with fiber layers and interlaminar resin layers as shown in Fig. 2(b). In Fig. 2(b), the fiber volume fraction in the fiber concentrated layer is 0.907 , which is the theoretical maximum fraction ${ }^{15,18)}$. The fiber concentrated layer was 
modeled using orthotropic shell elements. The thickness of shell element $t_{1}$ is calculated by

$$
\mathrm{t}_{1}=\mathrm{t}_{0}\left(\mathrm{~V}_{\mathrm{f}} / 0.907\right)
$$

, where $V_{f}$ denotes the fiber volume fraction and $t_{0}$ is the thickness of each layer, as shown in Fig. 2(a). These shell elements are connected with beam elements in the thickness direction in order to express interlaminar resin. These beam elements have various cross-sectional areas depending on their positions, the sum of the crosssectional areas in one interlamina was set to be the same as the whole laminate area. Figure 3 shows the modeling method of the test specimen used, GFRP. The difference between Fig. 3 and the quasi-three-dimensional model (Fig. 2) is the consideration of the outmost resin layers. In Fig. 2, the outmost layers were ignored. In Fig. 3, however, the outmost PM layers have large thickness. This suggests that the in-plane stress components caused in these layers cannot be ignored. To calculate these stress components, the outmost PM layers are modeled by isotropic shell elements. Namely, GFRP is assumed to be a laminated structure with the outmost PM, interlaminar $\mathrm{PM}$ and $\mathrm{GF}$, which are independently represented by an isotropic shell, beam and orthotropic shell element, respectively. As mentioned above all the shell elements are connected with beam elements in the thickness direction as shown in Fig. 3.

This modeling method can consider the heterogeneity of the used materials. This finding is a great advantage in the prediction of non-linear bending behavior, because failures of each type of element correspond to representative local failures.

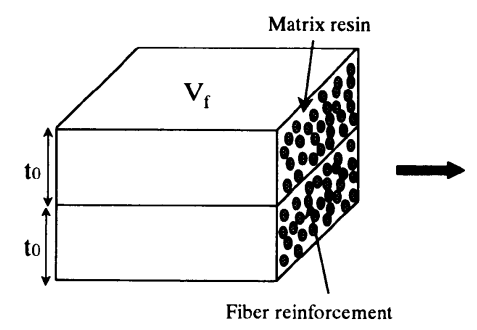

(a) Composite laminate(Two layers)

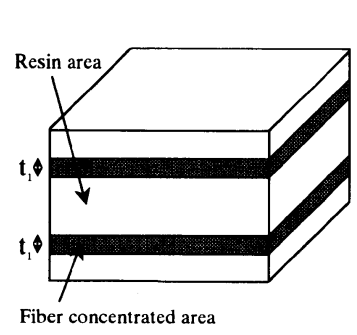

(b) Intermediate

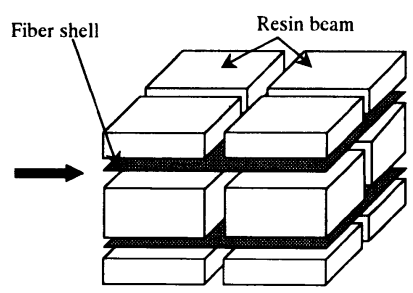

(c) Quasi-three-dimensional Model

Fig. 2 Basic concept for the quasi-three-dimensional model.

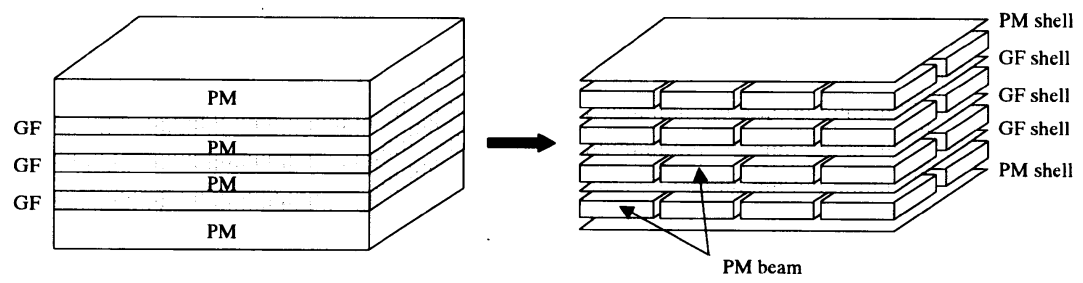

Fig. 3 Numerical model for the GFRP. 


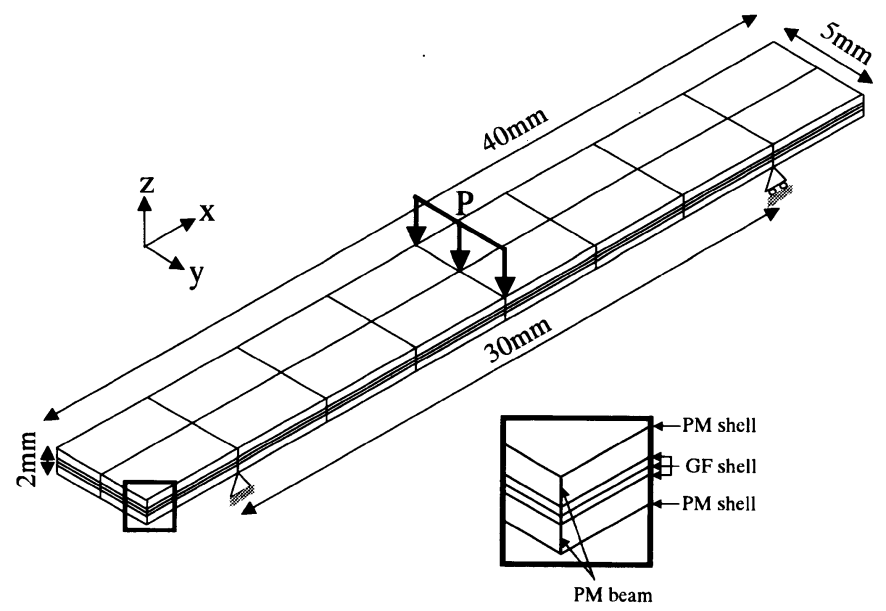

Fig. 4 Finite element model of the GFRP.

\section{Three point bending simulation by FEM}

Figure 4 shows the finite element model of the GFRP. The overall length of the model is $40 \mathrm{~mm}$, width is $5 \mathrm{~mm}$ and the thickness is $1.9 \mathrm{~mm}$. Here, $\mathrm{x}-, \mathrm{y}-$ and $\mathrm{z}$ directions show the longitudinal, width and thickness directions, respectively. For GF, warp and weft are $\mathrm{x}$ and $\mathrm{y}$ directions, respectively. The numbers of the shell elements, beam elements, and nodes are 80,108 , and 189 , respectively. The PM shell elements have a thickness of $0.63 \mathrm{~mm}$, this is equal to the thickness of the outermost PM layers. The GF shell elements have a constant thickness of $0.0948 \mathrm{~mm}$. This is derived from Eqn.1 and $V_{f}=0.43^{19)}$. The PM beam elements have a constant $0.2 \mathrm{~mm}$ thickness. This length is equivalent to the thickness of one GF layer. Since the GF shell is always placed on the neutral surface in the GF layers. Three point bending simulation using FEM was performed using the ADINA system on EWS (HP715/50, Hewlett Packard Inc.). The load condition was that the nodal forces were applied at the center on the top surface, and the load increment method ${ }^{15,20)}$ of about 14 steps was used. The load increment value was set to $4.9 \mathrm{~N}$. In every step, the normal and shear stress components produced in all elements are calculated. Some kinds of local failures can be observed until the final failure in case where the composite structures are loaded. Interlaminar delamination, transverse cracking and fiber breakage are representative and the effects of these local failures are quite different. Moreover, the failure of the outermost PM layer modeled by the shell element must also be predicted. In this simulation, the following three types of local failures, failures of PM shell, PM beam and GF shell elements are considered.

The failure of the outermost PM layer is represented by the yielding of PM shell element. An onset of the interlaminar delamination is represented by the yielding of the PM beam element. Von-mises criterion ${ }^{21)}$ is applied to the judgment of these. The criterion is given by 


$$
\mathrm{Y}^{2} \geqq{\sigma_{\mathrm{xx}}}^{2}+{\sigma_{\mathrm{yy}}}^{2}+{\sigma_{\mathrm{zz}}}^{2}+3\left({\tau_{\mathrm{xy}}}^{2}+\tau_{\mathrm{yz}}{ }^{2}+\tau_{\mathrm{zx}}{ }^{2}\right)
$$

, here $\mathrm{Y}$ denotes the shear strength of resin. $\sigma$ and $\tau$ denote the normal stress and shear stress values calculated. In the failed PM beam and PM shell elements, the elastic modulus was reduced to the strain hardening co-efficient, $\mathrm{E}_{\mathrm{f}}$. These material constants were measured by the short-span bending test ${ }^{22)}$ of the PM plate.

Both the transverse cracking and fiber breaking are represented by GF shell element failure. Tsai-Hill's criterion ${ }^{23)}$ is applied to the judgment. The criterion is given by

$$
\left(\mathrm{F}_{\mathrm{L}} / \sigma_{\mathrm{L}}\right)^{2}+\left(\mathrm{F}_{\mathrm{T}} / \sigma_{\mathrm{T}}\right)^{2}+\left(\mathrm{F}_{\mathrm{L}} \mathrm{T} / \sigma_{\mathrm{L}} \mathrm{T}\right)^{2} \leqq 1
$$

, subscript L, T and LT denote the warp, weft and shear directions, respectively. F and $\sigma$ denote the strength and stress values calculated. In this case the $\mathrm{L}$ and $\mathrm{T}$ directions are equivalent with longitudinal $(x)$ and width $(y)$ directions. Therefore, $\sigma_{\mathrm{L}}$ is significantly larger than other stress components. In other words, the equation can be simplified by

Table 1 Material properties used in this study

\begin{tabular}{cl}
\hline Element & \multicolumn{1}{c}{ Material properties } \\
\hline \multirow{2}{*}{$\mathrm{PM}$ (shell and beam) } & $\mathrm{E}=1.74 \mathrm{GPa}, \mathrm{NU}=0.4, \mathrm{den} .=1.2 \mathrm{~g} / \mathrm{cm}^{3}$, \\
& $\mathrm{Y}=4.90 \mathrm{MPa}, \mathrm{E}_{\mathrm{f}}=9.80 \mathrm{MPa}$ \\
\hline \multirow{3}{*}{$\mathrm{GF}$ shell } & $\mathrm{E}_{\mathrm{L}}=24.40 \mathrm{GPa}, \mathrm{E}_{\mathrm{T}}=22.20 \mathrm{GPa}, \mathrm{E}_{\mathrm{Z}}=5.76 \mathrm{GPa}$, \\
& $\mathrm{G}_{\mathrm{LT}}=4.80 \mathrm{GPa}, \mathrm{G}_{\mathrm{LZ}}=\mathrm{G}_{\mathrm{TZ}}=2.40 \mathrm{GPa}, \mathrm{NU}_{\mathrm{LT}}=0.3$ \\
& $\mathrm{~F}_{\mathrm{L}}=0.78 \mathrm{GPa}, \mathrm{F}_{\mathrm{T}}=0.70 \mathrm{GPa}, \mathrm{F}_{\mathrm{LT}}=0.48 \mathrm{GPa}$ \\
\hline
\end{tabular}

$\mathrm{L}, \mathrm{T}$ and $\mathrm{Z}$ denote warp, weft and thickness directions, respectively.

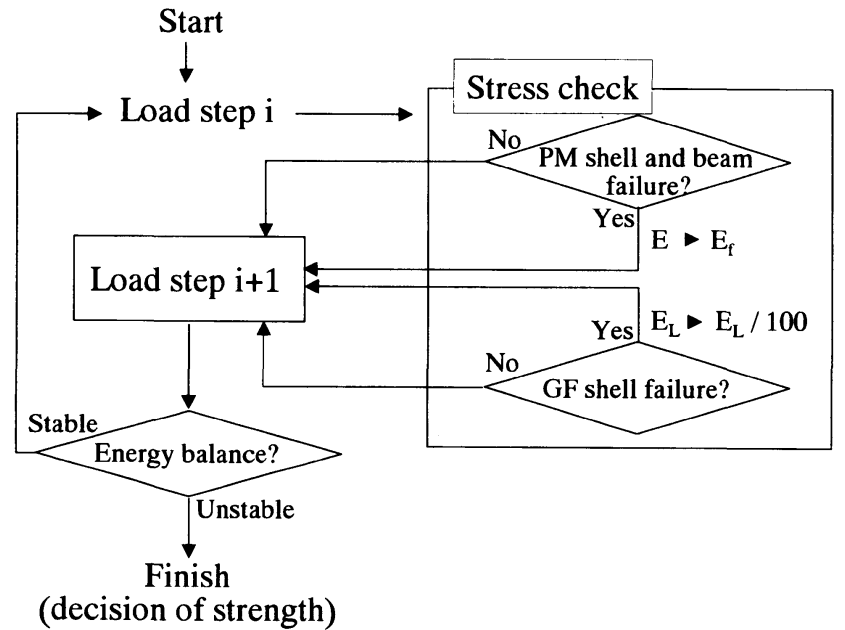

Fig. 5 Flow chart of the failure progress analysis of the GFRP. 


$$
\left(\mathrm{F}_{\mathrm{L}} / \sigma_{\mathrm{L}}\right)^{2} \leqq 1
$$

This simplification which is equivalent to the maximum stress criterion and means that the GF shell element failure corresponds to the fiber breaking. After GF shell element failure, the elastic modulus $E_{L}$ is reduced to $E_{L} / 100$. The reduction means the interrupt of stress transmission in the longitudinal direction. The material constants used are listed in Table 1. The process for analyzing the failure progress was summarized in Fig. 5.

\section{RESULTS}

\section{Experimental method}

Typical stress-deflection curves of the three types of specimens tested are shown in Fig. 6. It was confirmed that all types of specimens had a linear stress-deflection relation in the range of small deflections. The curve obtained from the GF straightly increased with an approximate constant modulus, and then reached final failure. On the other hand, a typical elastic-plastic behavior was obtained from the PM. For the above-mentioned GF and PM, the bending stress reached failure without rising or falling, whereas the curve of the GFRP had several failure points. It was clear that there were several kinds of local failure modes in GFRP. The failure strength $F$ and bending modulus $\mathrm{E}$ were calculated from the following formula:

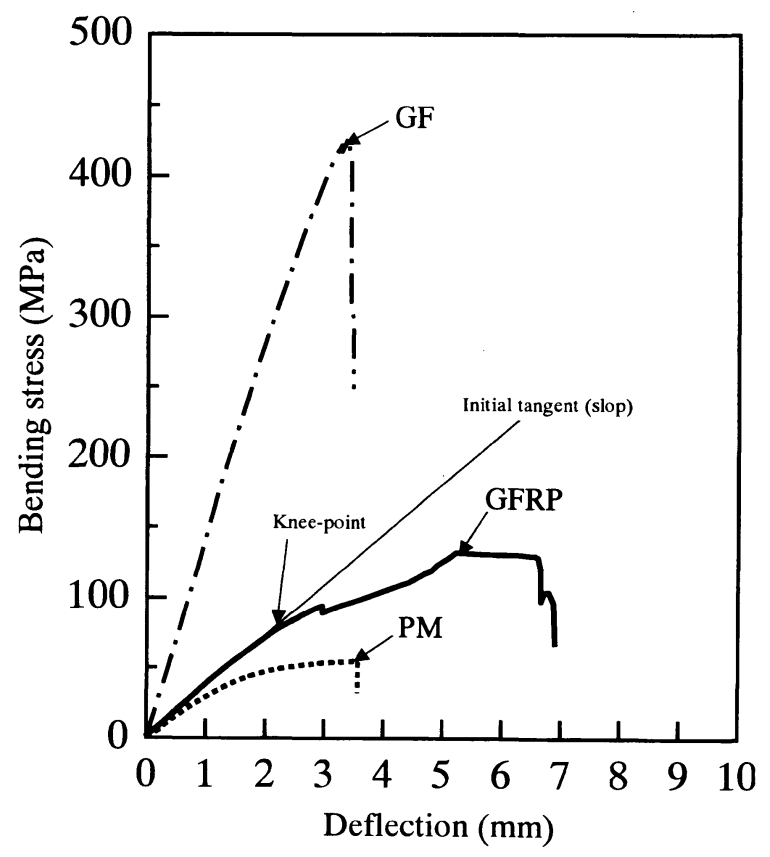

Fig. 6 Typical bending stress-deflection curves of three type specimens. 


$$
\begin{aligned}
& \mathrm{F}=(3 / 2)\left(\mathrm{P}_{\max } \mathrm{L} / \mathrm{bh}^{2}\right) \\
& \mathrm{E}=(1 / 4)\left(\mathrm{L}^{3} / \mathrm{bh}^{3}\right) \mathrm{k}
\end{aligned}
$$

where $P_{\max }$ is the maximum load, $\mathrm{L}$ is span length, $\mathrm{b}$ is width of specimen, $\mathrm{h}$ is thickness of specimen and $\mathrm{k}$ is the slope at the initial stage in the load-deflection curve. The experimental results of the bending properties which were obtained in the method described above are summarized in Table 2. The experimental results were the average of three measurements.

\section{Analytical method}

Figure 7 shows the relation between the bending stress and deflection obtained from the numerical simulation for GFRP. The reasonable agreements are evidence of load-

Table 2 Bending properties of three type specimens

\begin{tabular}{ccc}
\hline Code & $\begin{array}{c}\text { Failure strength } \\
\text { MPa (SD) }\end{array}$ & $\begin{array}{c}\text { Bending modulus } \\
\text { GPa (SD) }\end{array}$ \\
\hline GFRP & $126.4(6.3)$ & $3.0(0.02)$ \\
GF & $407.5(33.4)$ & $14.1(1.6)$ \\
PM & $54.1(0.1)$ & $1.7(0.02)$ \\
\hline
\end{tabular}

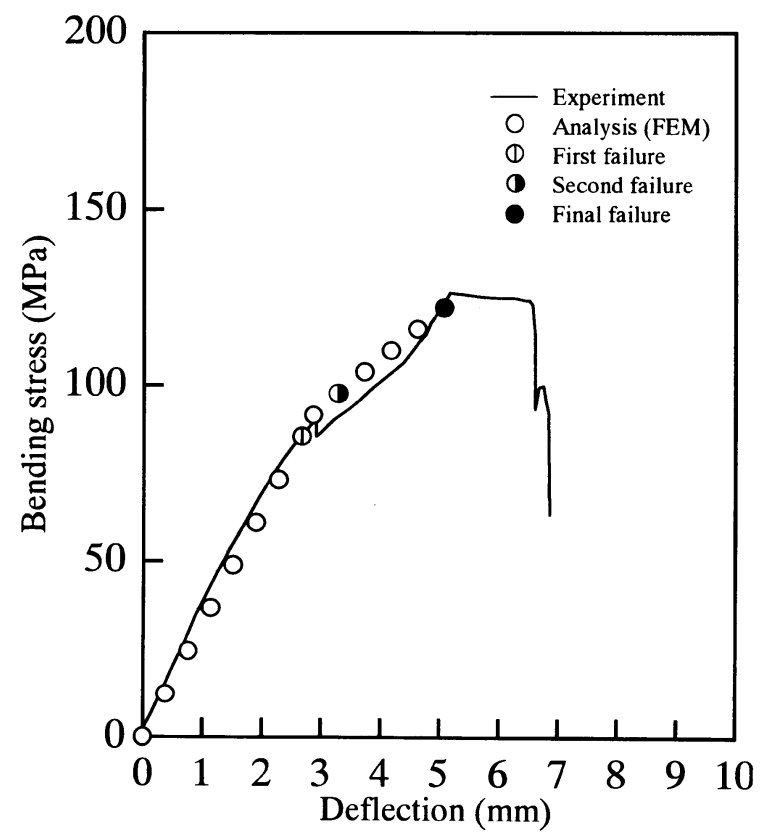

Fig. 7 The bending stress-deflection curves obtained from analytical and experimental results of the GFRP. 


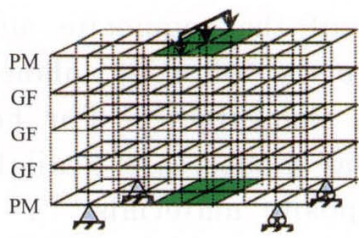

(a) $85.5 \mathrm{MPa}$ loading

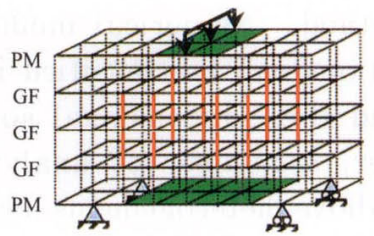

(b) $97.7 \mathrm{MPa}$ loading

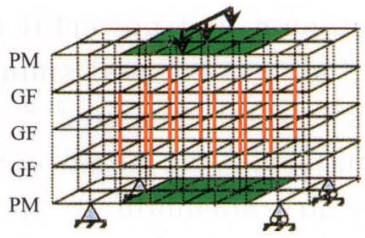

(c) $122.2 \mathrm{MPa}$ loading

I Yielded Beam Element

Damaged Shell Element

Fig. 8 Analytical failure progress process under three point flexural loading for GFRP.

Table 3 Comparison between analytical and experimental results of the bending properties for GFRP

\begin{tabular}{ccc}
\hline & $\begin{array}{c}\text { Failure strength } \\
\mathrm{MPa}\end{array}$ & $\begin{array}{c}\text { Bending modulus } \\
\mathrm{GPa}\end{array}$ \\
\hline Experiment & 126.4 & 3.0 \\
Analysis & 122.2 & 2.6 \\
Error $(\%)$ & -3.4 & -12.5
\end{tabular}

deflection relation in both results. Figure 8 shows the analytical failure progress of the GFRP obtained from the numerical simulation. In this Figure, bold red lines indicate the yielded beam elements and hatched green areas represent the failed shell elements. It appeared that the failure started at the outermost PM layer of the lamina as shown in Fig. 8(a). Then the PM beam element yielding spreads in the GF/GF interlamina with increasing bending stress. The first, second and final analytical failures are defined to be onset of PM shell failure, PM beam failure and maximum stress obtained, respectively. The first, second and final analytical failure stresses were $85.5 \mathrm{MPa}, 97.7 \mathrm{MPa}$ and $122.2 \mathrm{MPa}$, respectively. The analytical bending properties of the GFRP are summarized in Table 3, with the experimental results. The good agreements were obtained for failure strength and bending modulus.

\section{DISCUSSION}

The composite materials such as GFRP used in this study are heterogeneous materials composed of reinforced fiber and matrix resin. The composite materials can produce an excellent function by the interaction of the reinforcement fiber and the matrix resin. On the other hand, the failure progress behaviors of the composite materials is very complex compared with typical homogeneous materials ${ }^{24)}$. Since the failure progress usually implies various local failure modes such as interlaminar delamination ${ }^{25,26)}$, transverse cracks $^{27,28)}$ and interfacial failure ${ }^{29)}$ between the fiber and matrix. For the prediction of the above failure progress behaviors, the FEM is the 
most common and powerful method. Numerical models of the composite materials used in the conventional simulations can be classified into the following, plane strain elements $^{30)}$, shell elements ${ }^{31,32)}$ and three-dimensional solid elements ${ }^{33,34)}$. For homogeneous materials, as noted earlier, a number of analytical models are available but not they are adequate to the above heterogeneous composite materials ${ }^{1535)}$. Therefore, some models concerned with composite materials have been proposed ${ }^{36-38)}$. AbdEI-Naby et $a l^{35)}$ showed that the analysis of certain quasi-three dimensional problems about laminated composites can be performed using the general purpose finite element package. Hashagen et $a l^{39)}$ proposed a numerical model the so called solid-like shell elements for fiber us spelling throughout metal laminated composites. In the present study, we applied the quasi-three-dimensional model (Fig. 2) ${ }^{15-17)}$ for the GFRP, to predict the failure progress behaviors. The numerical modeling for GFRP was performed by combining the elements constructed independently for GF and PM (Fig. 3). The shell element is also connected to the beam element through the thickness. To check the validity of the numerical model of the GFRP, three point bending tests were performed experimentally. As experimental results, a significant difference in the bending properties was observed from the comparison between GFRP and PM (Fig. 6). The bending modulus of GFRP was significantly larger than that of PM. Shimozato et $a l .^{40,41)}$ reported that the carbon fiber reinforced denture base resins showed improved bending strength by $25 \%$ and tensile strength by $50 \%$. Fukuda et $a l^{42,43)}$ reported that the palatal area of carbon fiber and aramid fiber cloth reinforced denture bases exhibited about $50 \%$ and $40 \%$ thinning, respectively, compared with commercial denture base resin, but the stiffness and the strength of carbon fiber or aramid fiber reinforced denture bases were nevertheless similar to those of commercial resin denture base. However, these types of experimental research are inefficient, laborious, tedious, expensive and probably unsuccessful. The present study investigated the bending failure progress behaviors of GFRP from both the analytical and experimental viewpoints (Fig. 7). Several kinds of failures appear in GFRP with an increasing flexural load. The first analytical failure stress is in accordance with the experimental positions of the knee-point as shown in Fig. 7 . We decided that the outermost PM failure appears at the first experimental failure stress level, because the first analytical failure was represented by the shell element failure in the outermost PM near the loading point (Fig. 8(a)). Then, we must consider that the redistribution of the stress field in the GFRP was caused by this failure $^{44)}$. Accordingly, after the bending stress reached the first analytical failure stress, we continued the analysis by reducing the elastic modulus to the $\mathrm{E}_{\mathrm{f}}(\mathrm{Fig} .5)^{15)}$. With further increases in the flexural load, the yielding of the beam element, which corresponded to interlaminar delamination, spread in both the longitudinal and width directions. The GFRP used in this study showed results approximately similar to those of previous studies ${ }^{45,46)}$. At this level, the maximum loading was obtained. Namely, at the next load step of Fig. 8(c), no analytical result was obtained due to the divergence.

As mentioned above, the proposed model is a simplified numerical model. This 
suggests that the model has some fatal issues. For example this model cannot predict the volume constant and compressive modulus in the thickness direction. However, these issues have been not important parameters for practical designs. Judging from the described results and those of previous studies ${ }^{15-17,19)}$, it was confirmed that the proposed model, which considered the heterogeneity, had many advantages for the prediction of important design properties. As a consequence of modeling the fiber matrix separately, such as the numerical model of GFRP, it was confirmed that the different failure phenomena, such as interlaminar delamination and resin failure, can be simulated at the same time.

\section{CONCLUSIONS}

To analyze the bending failure progress of the GFRP, the numerical model was proposed. The proposed numerical model constructed with an isotropic shell, beam and orthotropic shell elements that correspond to the outermost PM, interlaminar PM and GF, was developed in this study. It was confirmed that the failure progress behaviors involving the local failures, such as interlaminar delamination and resin failure, could be simulated using the numerical model for analyzing the failure progress of GFRP.

\section{ACKNOWLEDGEMENTS}

This work was supported in part by a Grant-in-Aid for Encouragement of Young Scientists (No.11771248, No.13771189) from the Japan Society for the Promotion of Science, and by a Grant from the Ministry of Education, Culture, Sports, Science and Technology to promote 2001-Multidisciplinary Research Projects (in 2001-2005)

\section{REFERENCES}

1) Ohtani, T., Maeda, Y., Enomoto, K., Sogo, M., Okada, M., Nokubi, T. and Okuno, Y.: Study on denture repair cases Part 1. Suvey on resin denture base fracutures, $J J p n$ Prosthodont Soc 35 : 977-982, 1991. (in Japanese)

2) Vinson, J.R. and Sierakowski, R. L.: The behavior of structure composed of composite materials, Martinus Nijhoff Publishers : Chap.1, 1986.

3) Goldberg, A.J. and Burstone, C. J.: The use of continuous fiber reinforcement in dentistry, Dent Mater $8: 197-202,1992$.

4) Vallitu, P. K., Lassila, V. P. and Lappalainen, Rolf.: Transverse strength and fatigue of denture acrylic-glass fiber composite, Dent Mater 10 : 116-121, 1994.

5) Ladizesky, N. H., Cheng, Y. Y., Chow, T. W. and Ward, I. M.: Acrylic resin reinforced with chopped high performance polyethylene fiber-properties and denture construction, Dent Mater 9 : 128-135, 1993.

6) Inanaga, A., Naka, S., Takahashi, Y., Tachii, D., Yoshinaga, M., Habu, T. and Miyazaki, K.: Studies on denture base resins reinforced with carbon or aramid fibercloth Part 1. The effectiveness of including fiber-cloth and surface treatments, $J J p n$ Prosthodont Soc 37(5) : 1083-1090, 1993. (in Japanese)

7) Kanie, T., Fujii, K., Arikawa, H. and Inoue, K.: Flexural properties and impact strength of denture base polymer reinforced with woven glass fibers, Dent Mater 16:150- 
$158,2000$.

8) Onita, T., Nishiwaki, T. and Maekawa, Z.: The designing of vibration property for matrix hybrid laminates, Proceedings of the 7th Japan International Sampe Symposium: 491-494, 2001.

9) Zienkiewicz, O.C.: The Finite element method in engineering science, McGraw-Hill, New York, 1971.

10) Washizu, H., Miyamoto, H. Yamada, Y., Yamamoto, Y. and Kawai, T.: Yuugenyousohou Handbook Kisohen, Baifuudou Corp., Tokyo, 1981. (in Japanese)

11) Georgian, J.C.: Optimum design of variable composite flywheel, Journal of Composite Materials 23(1):2-10, 1989.

12) O'Neill. M. and Hollway, L.: Vibration characteristics of assemblies of graphitereinforced polyethersulphone tubes, Composites 21(1): 13-22, 1990.

13) Arnold, W.S., Marshall, I. H. and Wood, J.: Optimum design considerations for mechanically fastened composite joints, Composite Structures 16(1): 85-102, 1990.

14) Smith, P. A., Ashby, M.F. and Pascoe, K. J.: Modeling clamp-up effects in composite bolted joints, Journal of Composite Materials 21(10): 878-898, 1987.

15) Nishiwaki, T., Yokoyama, A., Maekawa, Z., Hamada, H., Maekawa, Y. and Mori, S.: A simplified tensile damage analysis method for composite laminates using a quasithree-dimensional model, Composite Structures 25 : 61-67, 1993.

16) Nishiwaki, T., Yokoyama, A., Maekawa, Z. and Hamada, H.: A new numerical modeling for laminated composites, Composite Structures 32:641-647, 1995.

17) Nishiwaki, T., Yokoyama, A., Maekawa, Z. and Hamada, H.: A quasi-threedimensional elastic wave propagation analysis for laminated composites, Composite Structures 32 : 635-640, 1995.

18) Hull, D.: An introduction to composite materials, Cambridge Solid State Science Series, London, 1987, pp.60-64

19) Onita, T., Nishiwaki, T. and Maekawa, Z.: Mechanical property of matrix hybrid laminates, The 9th US-Japan Conference on Composite Materials: 451-458, 2000.

20) Washizu, H., Miyamoto, H., Yamada, Y., Yamamoto, Y. and Kawai, T.: Yuugenyousohou Handbook Ouyouhen, Baifuudou Corp., Tokyo, 1983. pp.152-157. (in Japanese)

21) Yamada, Y.: Sosei Rikigaku, Nikkan Kogyo Shimbunsha, Tokyo, 1977, pp.47-50. (in Japanese)

22) JIS K 7057, Testing method for apparent interlaminar shear strength of glass fiber reinforced plastics, Japanese Standard Association, Tokyo, 1994, pp.498-500.

23) Jones, R. M.: Mechanics of Composite Materials, 3rd ed., McGraw-Hill, New York, 1975, pp.76-80.

24) Ikegaki, S., Sugimoto, K., Kameo, K., Sakaguchi, M., Masui, M., Nakai, A. and Hamada, H.: Flexural behavior of knitted fabric composites, Proceedings of the 5th Japan International Sampe Symposium : 28-31, 1997.

25) Brewer, J.C. and Lagace, P. A.: Quadratic stress criterion for initiation of delamination, Journal of Composite Materials 22(12) : 1141-1155, 1988.

26) Sun, C. T. and Manoharan, M. G.: Growth of delamination cracks due to bending in a $\left[90_{5} / 0_{5} / 90_{5}\right]$ laminate, Composite Science and Technology 34(4):365-378, 1989.

27) Favre, J. P. and Laizet, J. C.: Amplitude and counts per event analysis of the acoustic emission generated by the transverse cracking of cross-ply CFRP, Composite Science and Technology 36(1) : 27-44, 1989.

28) Lim, S. G. and Hong, C. S.: Effect of transverse cracks on the thermomechanical properties of cross-ply laminated composites, Composite Science and Technology 34(2): 145-162, 1989.

29) Nishiyabu, K. and Zako, M.: Effect of interphase properties on microscopic damage in embedded single fiber transverse tensile test, Proceedings of the 5th Japan International 
Sampe Symposium: 847-852, 1997.

30) Han, Y. M. and Hahn, H. T.: A simplified analysis of transverse ply cracking in crossply laminates, Composite Science and Technology $31: 165-177,1988$.

31) Whanthal, S. P. and Yang, T. Y.: Three-dimensional finite element formulations for laminated plates, Journal of Reinforced Plastics and Composites 10:330-353, 1991.

32) Burns, S. W. and Herakovich, C. T.: Efficient 3-D finite element failure analysis of comp. Loaded angle-ply plates, ICCM \& ECCM 5 : 231-241, 1987.

33) Tanchert, T. R.: Thermal buckling of symmetric angle-ply laminated plates, Composite Structures $4:$ 424-434, 1987.

34) Hang, Q. and Sankar, T.S.: Three-dimensional finite element formulation for stress analysis of anisotropic laminate structures, Comp. Mat, Design \& Anaysis : 189-200, 1990.

35) Abd-EI-Naby, S. F., Hollaway, L. and Gunn, M.: About the modelling of laminated composites, Composite Structures $26: 1-6,1993$.

36) Whitney, T. J. and Chou, T. W.: Modeling of 3-D angle-interlock textile structural composite, Journal of Composite Materials 23(9): 890-911, 1989.

37) Gu, Z. and Meng, L.: Prediction of notched strength of 3D carbon-carbon material under simple tension, Journal of Composite Materials 23(10): 997-1008, 1989.

38) Zhang, W.C. and Evans, K. E.: An analytical model for the elastic properties of fibrous composites anisotropic constituents, Composite Science and Technology $38: 229-246,1990$.

39) Hashagen, F., Schellekens, J.C.J. and de Borst, R.: Finite element procedure for modelling fibre metal laminates, Composite Structures 32 :255-264, 1995.

40) Shimozato, T., Yamanaka, A., Kurata, S. and Yamazaki, N.: Denture base PMMA resins reinforced with carbon fiber cloths Part 1. Surface treatments of the carbon cloths and its effects on bending and tensile strength of the reinforced resins, $J J$ Dent Mater 3 (5) : 648-654, 1984. (in Japanese)

41) Shimozato, T., Yamanaka, A., Kurata, S. and Yamazaki, N.: Denture base PMMA resins reinforced with carbon fiber cloths Part 2. Effect of thickness and number of carbon clothe sheets on physical properties of reinforced specimen, $J J$ Dent Mater 3(6) : 797-801, 1984. (in Japanese)

42) Fukuda, H. and Miyairi, H.: Effectiveness of reinforcement by carbon and aramid fibercloth to upper complete denture bases Part 1. Thinning of palatal area and flexural strength, $J J$ Dent Mater 7(2): 167-175, 1988. (in Japanese)

43) Fukuda, H. and Miyairi, H.: Effectiveness of reinforcement by carbon and aramid fibercloth to upper complete denture bases Part 2. Fatigue strength, $J J$ Dent Mater 7(6): 875-882, 1988. (in Japanese)

44) Lee, J. W. and Daniel, I. M.: Progressive transverse cracking of crossply composite laminates, Journal of Composite Material 24(11) : 1225-1237, 1990.

45) Altus, E. and Ishai, O.: Progressive transverse cracking of crossply composite laminates, Composite Science and Technology 39(1): 13-28, 1990.

46) Palley, I.: A fracture mechanics approach to interlaminar failure of unideirectionally reinforced composites, Journal of Reinforced Plastics and Composites 9(2): 174-181, 1990. 